\title{
Ensayos X. Poética-científica de Ezequiel Martínez Estrada
}

\author{
PABLO LUZURIAGA Universidad de Buenos Aires, Argentina / pabloeluzuriaga@gmail.com
}

\section{Resumen}

El ensayo a partir del cual E. Martínez Estrada se transforma en uno de los más importantes prosistas argentinos propone estudiar la historia y la cultura de su país a partir de una perspectiva metodológica que se define con la metáfora de una radiografía. Los rayos $\mathrm{X}$ prometen ver más allá de lo que se presenta frente a la retina. Nos encontramos ante una poética científica que desconfía de la observación y opta por el camino de la filología: leer al país como si fuese un texto escrito o un discurso que se oye. Pero la desconfianza que E. Martínez Estrada tiene sobre el sentido de la vista precede a Radiografía de la Pampa (1933). La semilla de esa sospecha germina en su obra poética temprana, en particular, en el camino que va del poemario Argentina (1927) a los dos volúmenes publicados en 1929: Títeres de pies ligeros y Humoresca. Entre ellos tiene lugar un punto de inflexión vanguardista que habilita, más tarde, la mirada de rayos X. Una perspectiva, la del radiólogo, que el autor argentino comparte con otras poéticas de la vanguardia que en los años veinte y treinta impugnaron al realismo ilustrado del siglo XIX.

Palabras clave: ensayo / poesía / vanguardia / rayos X / ciencia

\section{X-Essays. Scientific Poetry by Ezequiel Martínez Estrada}

Abstract

The essay from which E. Martínez Estrada becomes one of the most important argentine prose writers proposes to study his country's history and culture from a methodological perspective which is defined by the metaphor of an X-ray. X-rays allow us to look beyond what is presented to the retina. We find ourselves facing a scientific poetics that distrusts observation and chooses the path of philology: to read the Country as if it were a written text or a speech that is heard. But Martínez Estrada's distrust on the sense of sight precedes Radiografía de la Pampa (1933). The seed of that assumption germinates in his early poetic works, particularly, in the passage from the Argentina collection of poems of 1927, to the 1929 volumes titled Títeres de pies ligeros and Humoresca. Between them takes place an avant-garde inflection point that enables, later, the $\mathrm{x}$-ray view. A perspective, that of the radiologist, that the Argentine author shares with other poetics of the avant-garde that in the twenties and thirties challenged the illustrated realism of the nineteenth century.

Key words: essay / poetry / avant-garde / X ray / science

Fecha de recepción: 6/12/2017, fecha de aceptación: 6/3/2018

Para citar este artículo: Luzuriaga, Pablo (2018). «Ensayos X. Poética-científica de Ezequiel Martínez Estrada». El taco en la brea 7 (diciembre-mayo) 144-158 Santa Fe, Argentina: UNL. DOI: https://doi. org/10.14409/tb.voi7.7361 
Desde Montaigne, a lo largo de la modernidad y hasta el presente, el género del ensayo se inscribe sin límites precisos, preceptivas ni reglas, en una zona difusa entre la ciencia y el arte. Traza caminos que reúnen los campos de la investigación, el conocimiento, las poéticas, la belleza, la retórica, el goce y la interpretación. Se trata de un género paradójico: su desarrollo es paralelo al proceso de secularización, a la especialización de las esferas de la cultura, a la autonomía relativa del arte respecto de la ciencia y la moral; pero contradice el supuesto moderno que separa las estructuras de la racionalidad cognitivo-instrumental, la moral-práctica y la estético-expresiva: el ensayo se hilvana entre esas estructuras y escapa al recorte de los especialistas. Entre fines del siglo XVIII y el XX, asistió a un proceso de autoconciencia. Las poéticas del romanticismo, del modernismo y las vanguardias responden a la especialización: el arte replegado sobre sí se hace crítica del mundo. El ensayo surrealista, la propuesta de W. Benjamin (Calle de dirección única, 1928; «El surrealismo, la última instantánea de la inteligencia europea», 1929; Libro de los pasajes, 1940), expresa el mayor grado de emancipación del género respecto de las demás esferas de la cultura: réplica, a un tiempo, de las convenciones del historicismo y el positivismo científico. El estudio de la sociedad no es un apéndice —ni necesita del instrumental léxico—-de las ciencias naturales para abordar su objeto, la historia no se puede reconstruir eludiendo el tiempo que nos separa de la época que nos proponemos estudiar y la escritura acerca de ese objeto no es un mero instrumento de comunicación sino una herramienta de inteligibilidad.

Las conexiones entre ciencia y arte trazaban, antes de su relativa autonomía, fronteras difusas en De la naturaleza de las cosas - el poema científico de Lucrecio- hace dos mil años y en los Vedas hindúes hace más de tres mil años. Pero la autonomía es relativa porque también hay conexiones entre arte y verdad en la zoología humana de Balzac hace apenas dos siglos e, incluso, en la fórmula clave de Adorno, el arte que mira hacia sí mismo no deja de ser investigación del mundo. La reproductibilidad técnica moderna desde la imprenta al cine produjo uno de los impactos materiales más grandes en la historia de las artes. ¿De qué forma afectó al género del ensayo? La ciencia investiga y la técnica resuelve el quehacer; si las poéticas son también modos de investigar, la reproductibilidad trastocó sus fundamentos. Un abordaje adecuado de la problemática debería completar este aspecto de la relación entre arte y ciencia —las transformaciones técnicas de la producción artística - con otros: la imaginación científica y los laboratorios imaginarios de las artes, las explicaciones científicas sobre la estética de la recepción o las relaciones entre el problema de la verdad en filosofía, ciencia y arte; pero el análisis específico de la innovación técnica durante el largo período del modernismo (Williams) continúa siendo un punto de partida fundamental y, a pesar de la enorme cantidad de estudios que existen al respecto, todavía necesario.

Esta etapa del ensayo en América Latina ha sido estudiada de forma parcial. En autores como Ezequiel Martínez Estrada, Gilberto Freyre, Fernando Ortiz, Benjamin Subercaseaux, no se han señalado puentes y conexiones de peso que relacionen ensayo y vanguardia artística. En general, en la crítica ha primado el supuesto que separa las esferas del «pensamiento» latinoamericano respecto de las prácticas del arte; un criterio historicista que aborda los años veinte y treinta a favor del sentido que ha tomado la historia (Devés Valdes). Las vanguardias históricas en América Latina fueron revisitadas en los sesenta y setenta por los movimientos artísticos y todavía nutren al arte del presente. En cambio, la ensayística de los años treinta y cuarenta fue obturada por la institucionalización de las ciencias sociales al promediar el siglo (Devés Valdés). El «fracaso» del programa vanguardista, destruir el arte para conectarlo con la vida, se transformó en éxito: el arte 
como crítica de las instituciones en el arte contemporáneo; el «fracaso» de los ensayos gobernados por la «intuición», las «impresiones» o el llamado «capricho estético» pareciera no haberse transformado en nada frente al éxito la Teoría Crítica, la Sociología o la Ciencia Política. Martínez Estrada es recordado más por «su pluma» que por los aciertos sobre la realidad argentina que expone en sus escritos, como si «pluma» y acierto fueran por caminos separados.

Las transformaciones en el arte como investigación —reflexión sobre la percepción—consideradas desde el punto de vista de las innovaciones técnicas para la producción, impactaron de forma decisiva en la ensayística. Martínez Estrada desplegó su "poética científica» sobre las mismas alteraciones que afectaron a las vanguardias. Su obra más conocida, Radiografía de la Pampa (1933), se concibe a partir de la crisis en las técnicas de percepción que tuvo a las artes y las ciencias como medios de reflexión privilegiados. En el ensayo radiográfico la crisis de la percepción se manifiesta como un doble distanciamiento: respecto de determinismo positivista y de la versión idealista del modernismo darío-lugoniano. Central en la historia del ensayo argentino, el libro como punto de partida cuestiona la relación entre percepción y conocimiento. Las evidencias que captamos a través del sentido de la vista son engañosas, debemos sospechar de ellas, no son más que la superficie aparente de un mundo mucho más complejo que es necesario interpretar. Contra la contemplación objetivista, prima un sentido especulativo que atiende a las fuentes del lenguaje. Después de la crisis económica mundial de 1929 y de la crisis política nacional de 1930, responde a la tradición del pensamiento argentino como una crítica a los discursos superficiales que justifican el proceso de modernización del Estado. La férrea identidad nacional argentina, forjada al calor de la batalla contra la cultura disolvente de la inmigración masiva, muestra los puntos de soldadura al señalar el choque entre los inmigrantes y las matrices profundas de la colonia. La técnica radiográfica devela estructuras profundas que se esconden en la sociedad argentina, detrás de las «seudoestructuras» de la modernización inorgánica.

La metáfora de los rayos $\mathrm{X}$ se inscribe en dos series. Un eje horizontal la encadena al rechazo que las vanguardias hacen frente a las convenciones de la mímesis heredadas del siglo XIX; en un eje vertical, la metáfora se enlaza a los contrastes internos de la obra de Martínez Estrada. La mirada que atraviesa cuerpos opacos nace junto a una decisión clave en la trayectoria del escritor argentino: marginar la poesía y dedicar sus esfuerzos a la prosa. La lectura atenta de las transformaciones y divergencias al interior de su producción poética permite entender esa determinación como un resultado; consecuencia de un proceso coherente de maduración del proyecto artístico-intelectual que engloba las distintas prácticas de escritura en prosa, sea el ensayo o la poesía, la narrativa o el teatro. La mirada de rayos $\mathrm{X}$ es un capítulo de una reflexión mayor sobre el lenguaje literario. Desde una primera etapa ingenua, modernista y apoyada en el sentido de la vista, se desencadena el pasaje a una segunda etapa marcada por una actitud de sospecha característica de los movimientos de vanguardia, apoyada en el sentido de la escucha y en la lectura. En los libros de poesía predice el cambio: las exigencias por las cuales fue necesario abandonar la escritura en verso y volcarse a la prosa, al inicio de la década del treinta, tienen lugar por primera vez en los libros de poesía que publica en 1929. Los rayos X, como metáfora perceptiva, vienen de las vanguardias en auxilio de una obligación intrínseca al proyecto literario. El desplazamiento se hace evidente al contrastar Argentina, el libro de poesía publicado en 1927, con Radiografía de la 
Pampa. Porque son dos versiones por completo distintas de una misma búsqueda: interpretar al país. El eje vertical se desplaza de la ingenuidad a la sospecha; el tránsito se explica en el punto de inflexión: entre ambas interpretaciones median dos libros, nos referimos a los volúmenes de 1929, Títeres de pies ligeros y Humoresca.

\title{
Eje vertical: de Argentina (1927) a Radiografía de la Pampa (1933)
}

La poética vanguardista que impulsa a Radiografía de la Pampa, tanto como la prosa en la que se desarrolla el ensayo, contrastan con los primeros libros publicados por el joven poeta. Hasta la publicación de su primer ensayo, por el que fuera reconocido como uno de los más importantes prosistas argentinos, había publicado seis libros de poesía entre 1918 y 1929 y había recibido, por ellos, importantes premios nacionales y municipales. El ensayo de los rayos X no puede leerse sino como respuesta a esa obra anterior, es producto de una búsqueda artística que había desarrollado en verso y que a partir de la década del treinta continúa a través de la prosa. Interesa aquí mostrar el pasaje del poemario Argentina, de 1927, a Radiografía de la Pampa, de 1933, porque uno y otro son un mismo libro, escrito dos veces: una versión modernista —en el sentido de R. Darío-, idealista, que confía en la retina y otra bajo el influjo de la sospecha propia de la poética vanguardista.

Dos lecturas del país. La primera es la versión ingenua —el positivo—, la segunda, su reescritura suspicaz en clave de radiólogo vanguardista —el negativo—. En 1927, el "yo poético» sin fisuras observa al país con plena confianza en el ojo desde la cumbre de una montaña a la que accedió volando. Así comienza el poemario. La posición es la de quien contempla un cuerpo del que se ha desprendido.' El poeta canta desde un mirador, punto privilegiado para la visual: «Estoy todo en los ojos. Mi vista aguda y vasta» (Martínez Estrada 1947:143). ${ }^{2}$ Pero — como anticipación de lo que vendrá - tras ser encumbrado, el ojo es relativizado. El poema siguiente refiere a la sonoridad del cuerpo - singular realismo grotesco que viene de poemarios anteriores-, al definir su actividad como la de quien ausculta con el estetoscopio, forma primitiva —ingenua - de su máquina de rayos X. La figura poética preludia la búsqueda posterior del ensayista: atravesar superficies. La versión ingenua anticipa, tímida, el pasaje de la vista al oído, pero aún sin salir del paradigma visual, aéreo, externalista del observador (médico-estetoscópico) privilegiado.

La primera unidad de este largo poema de 1927 eleva al poeta y lo ubica frente al país, el gigante. La segunda parte pierde la unidad de la voz en la «escucha estetoscópica» — puras imágenes hechas con palabras - acerca de aquello que el gigante cobija en su interior. La voz sale para escuchar adentro, vuela para ver las estructuras. La mirada — confiada en lo que tiene frente a los ojos— se diluye en los objetos: ellos completan al país como un extenso catálogo. Dos ejemplos, de los más breves, permiten caracterizar el particular objetivismo de Argentina:

\author{
El Avestruz \\ Con irrisorio donaire \\ que el susto quiebra, ligero \\ dispara con su plumero \\ sacándole el polvo al aire. (189)
}


Pingüinos

\author{
Vestidos con su librea \\ y su camisa de plancha \\ toman asiento en la ancha \\ paleolítica platea. (189)
}

Dos personificaciones, el avestruz inflado de carácter — donaire-y el pingüino «vestido», cuyo sentido es explicado en función de los movimientos que realiza en el espacio. La unidad de los versos es fotográfica (Barthes): el avestruz, eléctrico, «dispara» cuando se asusta; el pinguiino, calmo, se sienta en su «paleolítica» platea: las cuevas — cavernas - de Punta Tombo, provincia de Chubut. Ambas estrofas son redondillas, cuatro octosílabos en rima consonante abrazada (abba), estructura que aporta al poema cohesión y síntesis. La rima captura el movimiento, a la manera de un haiku, pero de cuatro versos - estructura que Martínez Estrada desarrolla años más tarde en Coplas de ciego, 1959- Los dos primeros versos ofrecen información al efecto de personificación, el tercero se inicia con la acción del verbo y el último, de cierre, comunica sobre las consecuencias del movimiento en el espacio. Los poemas definen la imagen característica de animales elegidos como porción de una identidad global auscultada desde la altura. Los procedimientos poéticos devienen en método cognitivo: «percibir» la pauta objetiva de estas unidades de análisis, implica atravesar un camino que transita por el lenguaje, la personificación y la mirada subjetiva. De esta manera se desarrolla el «objetivismo» de Argentina, a distancia de los volúmenes de poesía que lo preceden, en los que el «yo» poético que se hace presente en los prólogos, epílogos, y continúa como tema en poemas que reflexionan sobre sus cualidades al interior de cada libro.

El avestruz y el pingüino son apenas dos partes del todo. Como ellos, aparecen otros tantos objetos de análisis poético: «La estancia», «La doma», «La vaca», «La oveja», «Arada», «Siembra», «Siega», «Trilla», «El mate», «San José de la Esquina», «Iberá», «Córdoba», «Nahuel Huapí», «Montañas», «Pampa Central», «Salitrales», «Petróleo», «Río Paraná», «El obrajero», «Frutas», «Hortalizas», «La uva», «El ombú», «El vizcachón», «Sábado», «Romerías españolas» y «Buenos Aires»: unidades, como dice en el séptimo poema, de lo actual, lo vivo, lo que es, se hace, se piensa y se prepara. En las que el «yo», que mira desde lo alto, se retira y contempla. Se trata de una lógica iterativa invertida años después por «El aleph», el cuento de Borges en el que Carlos Argentino Daneri es artífice del poema «La tierra», con el que el autor de «El jardín de los senderos que se bifurcan» responde a la novela Cancha larga: novela del campo argentino (1939) de Eduardo Acevedo Díaz y, al mismo tiempo, conmina al olvido obras como Canto a la Argentina de Darío o las Odas seculares de Lugones.

Seis años más tarde, la lectura que el novel ensayista propone del país se realiza en contraste a la del joven poeta. El supuesto con el que comienza Radiografía de la Pampa (1933) invierte el paradigma visual, aéreo, externalista del observador —-médico-estetoscópico — privilegiado de Argentina (1927). Hablar del mundo es hablar de cosas dichas, escritas y soñadas; no tanto de cosas vistas desde afuera y auscultadas. Referir a la realidad argentina y latinoamericana es tratar con el lenguaje, como haría un filólogo; pero también con la imaginación, con los sueños, cristalizaciones culturales de capas retóricas, maneras de decir que son maneras de ser que se escuchan y se leen. De esta manera comienza la radiografía: 
El nuevo mundo, recién descubierto, no estaba localizado aún en el planeta, ni tenía forma ninguna. Era una caprichosa extensión de tierra poblada de imágenes. Había nacido de un error, y las rutas que a él conducían eran como los caminos del agua y del viento. Los que se embarcaban venían soñando; quedaban soñando quienes los despedían. Unos y otros tenían América en la imaginación y por fuerza este mundo, aparecido de pronto en los primeros pasos de un pueblo que se despertaba libre, había de tener formas de ambición y soberbia de un despertar victorioso. Es muy dificil reproducir ahora la visión de ese mundo en las pequeñas cabezas de aquellos hombres brutales, que a la sazón estaban desembarazándose de los árabes y de lo arábigo. ¿Qué cateos imaginativos realizaban el hidalgo empobrecido, el artesano sin pan, el soldado sin contrata, el pordiosero y el párroco de una tierra sin milagros, al escuchar fabulosas noticias de América? Mentían sin quererlo hasta los que escuchaban. Un léxico pobre y una inteligencia torpe habían de enriquecer la aventura narrándola. Los mapas antiguos no pueden darnos idea aproximada de esos otros mapas absurdos de marchas, peligros y tesoros dibujados de la boca al oído. (Martínez Estrada 1933:5, el subrayado es nuestro)

Las primeras líneas de Radiografía de la Pampa exponen una poética vanguardista, en el sentido surrealista: la realidad consciente, superficial, retiniana, es parcial; el sueño le gana la partida al ideal. Reproducir la visión del mundo de los conquistadores es muy difícil, nos dice, y refiere a la cabeza de «esos hombres brutales» que estaban «desembarazándose» de los árabes y lo arábigo: la visión está mediada por la imaginación. ¿Qué imaginaban al escuchar sobre América? ¿Qué mapas se dibujan de la boca al oído? Mapas de lenguaje. Nos encontramos ante una lectura del país impresa en negativo respecto del poemario Argentina. El radiólogo, al revés del poeta, no se eleva por encima de los demás para ver como un genio una totalidad retaceada al común de los mortales, sino que se interna en la selva espesa del lenguaje, único medio para acceder a la historia, la cultura y la realidad profunda del país. Entre la ingenua lectura modernista darío-lugoniana y la lectura escéptica radiológica se encuentra el punto de inflexión. Dos libros: Títeres de pies ligeros y Humoresca, juntos, son el capítulo vanguardista de su poesía. En ellos estalla la mirada ingenua y nace la ciencia del radiólogo. Fueron publicados en 1929, el mismo año de la crisis económica.

\section{Punto de inflexión: 1929. Poesía de vanguardia}

En 1929, la fase vanguardista de la poesía de Martínez Estrada lleva a cabo un procedimiento de sustracción. ${ }^{3}$ Elimina la identificación que los versos y el canto mantenían con el «yo» poético. Como consecuencia de la sustracción, es desechada por completo la mirada ingenua que pretendía ver el mundo desde la unidad de la primera persona: nace — en verso - la desconfianza en la retina. La etapa que aquí concluye en su producción poética se abre con Oro y piedra (1918) y se extiende hasta Argentina (1927). A esta etapa pertenecen también Nefélibal (1922) y Motivos del cielo (1924). Se trata de un ciclo donde los temas aéreos son determinantes, marcado por la atmósfera del Ariel de Rodó y las estéticas modernistas de Darío y Lugones; aunque se distancie de esa sensibilidad por la influencia contraria de una lectura temprana de Nietzsche. Desde el primer poemario, el filósofo alemán gravita entre los versos anclando en tierra todo impulso hacia el cielo y el aire. ${ }^{4}$ En Argentina (1927), la contradicción parece solucionada. El poeta asciende a lo alto de una montaña y observa al gigante - distante de la autorreflexión que predomina en los primeros libros - como un médico autorizado. Es el libro objetivista: «Estoy todo en los ojos».

Pero el «yo» poético que en dialéctico ascenso había llegado a lo más alto, en 1929, es dado por muerto. El paradójico «Prólogo del lector» que abre Títeres de pies ligeros y el poema «Ezequiel 
Martínez Estrada» de Humoresca toman posición sobre la obra precedente, eliminan la relación entre autor y «yo» poético, y destierran por completo la fuerza centrífuga de todo lo solemne que hay en la obra temprana. El desplazamiento transita de Lugones a Macedonio Fernández. La palabra escrita pierde por completo la intención de la palabra dicha. Títeres de pies ligeros y Humoresca son dos volúmenes de poesía vanguardista. El primero es la contracara de Argentina. Una obra teatral en verso sobre marionetas, héroes de una historia que no sale de las tapas del libro: a su término los títeres quedan tendidos en un rincón. Humoresca es la carta de despedida de la poesía: destrucción vanguardista de la institución artística, un libro consciente de que es el último. En él radica el alto grado de cohesión de este sistema poético. Los versos se despiden de sí mismos hasta nuevo aviso, treinta años más tarde, cuando Martínez Estrada publique Copas de ciego, en 1959.

Si los primeros libros seguían el presupuesto romántico de enlazar el mundo clásico con el moderno; en las publicaciones de 1929, el pasado al que se refiere es el legado modernista: Humoresca está poblada por Leopardi, Heine, Whitman, Emerson, Baudelaire, Poe, Valery y Horacio Quiroga. Títeres de pies ligeros ingresa en la serie de referencias a la Comedia del Arte Italiana de los siglos XVI y XVII retomada por el arte moderno. ${ }^{5}$ La compilación de su poesía temprana, editada por el autor en 1947, ubica la obra teatral en verso delante de Humoresca. ${ }^{6}$ Pero ambos libros fueron publicados el mismo año e incluso en la primera edición de Humoresca aparece Títeres de pies ligeros entre los libros publicados por la misma editorial Babel. Martínez Estrada decide que un volumen se ubique delante del otro en el orden que asigna a su obra en verso. Entre Argentina y Títeres... se produce el contraste más pronunciado de la compilación y Humoresca cierra el ciclo amplio de la escritura en verso.

En efecto, el punto de inflexión de 1929 se consuma con la lúdica «humoresca». En este libro da muerte al «yo» poético que confiaba en la retina y elimina cualquier pretensión objetivista del proyecto literario. Los poemas que abren el volumen están incluidos dentro de un título general: «YO, TÚ, ÉL». El primero es una autobiografía mínima que se titula con su nombre: «Martínez Estrada», donde incluye una serie de poemas de cuatro versos, también con subtítulos, el primero de los cuales es el «Prólogo» y el último el «epitafio», que cierra con el verso: «Y, sin embargo, aquí estoy, muerto» (74). El poema es la historia del proyecto literario en verso cuya publicación a partir de este libro suspende por treinta años y reemplaza por el proyecto en prosa. En la autobiografía repasa los poemarios anteriores e incluso alude a la recepción del proyecto literario. Pero se da por muerto. La crítica, que en raras ocasiones atiende a estos detalles, leyó el abandono sin explicar la existencia de las Coplas de ciego. Lo que muere no es la poesía en sí sino el proyecto poético, en el sentido ingenuo que tuvo hasta 1927.

En general, la decisión ha sido leída como la de un escritor que renunció por completo a la poesía para dedicarse a la prosa, como si la primera fuera un oficio irresponsable en comparación con los males del país que era necesario atender. Las coplas publicadas en 1959 niegan que haya abandonado por completo la escritura en verso y su «ceguera» está conectada de forma intrínseca a la poesía temprana y explica los rayos X. Porque Humoresca, además de asesinar al «yo» poético, destierra la idea misma de la representación visual. En «Variaciones sobre un tema en Baudelaire» -la primera de las tres variaciones que siguen a «YO, TÚ, ÉL», dedicadas también a un tema en Leopardi y un tema en Válery—, tiene lugar la reivindicación definitiva de la materia —el mineral, la piedra - por sobre la contradicción con el mundo ideal:? «Antes tenía horror intelectual/a esa fuerza fatal/ que enclava en tierra al vegetal/;Ignoraba la dicha total del mineral!» (279). Después 
del suicidio en «Martínez Estrada», en esta «Variación de Baudelaire» vuelve el tono prologal para referir a la diferencia entre el presente y los primeros libros de poesía:

\section{$\mathrm{V}$}

Caí en cuerpo efímero y busqué la manera de abrir brechas para irme de allí con la mirada, y para que la luz llegara desde fuera.

Abrí cuatro ventanas que daban a la nada.

Y una vez horadados los muros me asomé y vi el vacío enorme. Y ese vacío duro ocupó las ventanas, más compacto que el muro. Es peor esa tapia que la que yo quité. (279)

VI

Cantamos, pero sólo para olvidar la vida, y el cantar con los ojos cerrados, es de horror. Y caeremos, cantando, con la brutal caída de Ofelia, que se mata por cortar una flor.

VII

Soy una isla abrupta en un mar inviolable, inviolable a sus ímpetus e infinita como él. Le he puesto al universo la linde infranqueable de mi cuerpo. Interpongo entre él y yo mi piel.

Pero el poder que mueve al mar enloquecido también penetra en mí y me agita a su antojo. Me invade con su bárbaro fragor por el oído. Se me va el alma al mundo por el puente del ojo.

VIII

Voy rodando hacia el fondo del abismo.

Tal vez no tenga fin esa caída,

porque ese precipicio soy yo mismo.

Sólo me cuesta, ese traspié, la vida. (279-280)

Como el albatros de Baudelaire, cayó. Aquí, en su propio cuerpo desde las alturas: de la montaña de Argentina. El primer hemistiquio refiere con el verbo a la primera etapa (1918-1927) y cierra: «en 
cuerpo efímero». Materia que se degrada, carne que se pudre si queda al aire, comida por gusanos. Desde el cuerpo efímero - antes negado — pretende volver a salir, pero afuera del cuerpo no hay nada. La palabra escrita, «caída», en el cuerpo — lejos del ideal— no ve, es ciega. Esa misma escritura, hecha cuerpo, luego, al expandirse en la prosa desconfía de la mirada retiniana y atraviesa las superficies con rayos X. Pero antes de dispersarse, y por eso el movimiento hacia la prosa, la poesía se reconoce limitada: la isla en el mar inviolable es el círculo cerrado de la escritura en verso que no sale de sí misma. Entre ella y el mar interpone la piel: el cuerpo, la palabra escrita. El mundo penetra en la palabra escrita y la agita; el mundo invade "por el oído». Es la inversión de Argentina; ahora, se «le va el alma al mundo por el puente del ojo» (280) y de regreso entra por el oído. La poesía es ciega, su asunto ingresa por la oreja. La palabra escrita es una imagen auditiva. La radiografía opera sobre el lenguaje. La historia está hecha con capas de lenguaje, ilusiones y sueños incompletos, cristalizaciones que el radiólogo investiga. La vanguardia suprime el monolingüismo de la poesía y habilita al dialogismo de la prosa.

\section{Eje horizontal: radiografía y vanguardia}

La radiografía es el método de indagación de una poética que desconfía de las evidencias retinianas. En tanto poética, sospecha de la mímesis superficial del naturalismo y el realismo; en tanto indagación científica, del determinismo positivista y la razón. Para hablar del país no hay que atender ni a las estadísticas ni a las evidencias visuales; sino al lenguaje, la imaginación y la cultura. Los rayos X salen de los ojos de un lector —no de un observador-, están más cerca del trabajo de un filólogo que de la tarea de un biólogo naturalista. Atraviesan capas de sentido superpuestas, cristalizaciones discursivas, y acceden a una realidad que no se presenta a la vista. La radiografía es una técnica de observación que como principio quiere develar lo que no es evidente a los ojos. El producto en la placa no es general, sino que es orgánico, poroso. El resultado no son Leyes generales, sino conocimientos singulares.

El título del libro ofrece un método de investigación. Como metáfora la radiología fue asumida por distintas poéticas de la vanguardia. ${ }^{8}$ Los rayos X coincidieron con una necesidad: desconfiar de las imágenes que se nos presentan como verdades incuestionables. La metáfora se extendió como recurso que por analogía ponía en crisis al realismo mimético. Los registros infraleves en vidrio y los visores portables traslúcidos de Duchamp, las imágenes metafísicas de De Chirico, la analogía de Picabia entre su pintura y el realismo a propósito de la relación entre las radiografías y la fotografía, los futuristas que se arrogaron la capacidad de ver a través de la opacidad de los cuerpos, los rayonistas rusos que consideraban la realidad como un entramado de radiaciones electromagnéticas que la pintura debía registrar, las danzas luminiscentes de Fuller y el contundente cuestionamiento que el cubismo dirigió al arte retiniano tuvieron como antecedente imaginario la mirada de rayos X que Röntgen descubrió en 1895, mientras trabajaba con radiaciones.

La «poética radiográfica» le permite a Martínez Estrada componer su artefacto cognitivo. Es la solución del primer ensayo sociológico ${ }^{9}$ elaborado por un poeta que dejó de escribir versos por desconfiar del objetivismo. La radiografía responde de forma directa a una coyuntura histórica: la crisis que afectó a nuestro país a partir del golpe de Estado de 1930. Crisis de legitimidad política iniciada aquel año junto a la crisis económica que afectó Occidente tras el viernes negro de 1929 e hizo caer el telón del «optimismo decimonónico», el supuesto mitrista de que Argentina era un país excepcional dentro de América Latina, de que estábamos guiados por un «destino de 
grandeza» y que nuestra geografía nos devolvería un futuro de riquezas inagotable. El discurso de Mitre y «la civilización» de Sarmiento son la superficie visible del optimismo retiniano, narrativa que se volvió cáscara superficial y sospechosa a partir de la crisis. Pero la placa radiográfica tomada sobre el territorio de la Pampa es accionada por el mismo impulso que lleva a los cubistas a anunciar el fin del siglo XIX, como término de una etapa de ingenuidad objetivista, y el nuevo siglo como aquel que sospecha de las fachadas aparentes. ${ }^{10}$

Debajo de las superficies, de las coyunturas, corrientes profundas guían el movimiento del océano; debajo de la piel, los huesos sostienen el cuerpo. En el último capítulo de su estudio sobre la Pampa, Martínez Estrada desarrolla el concepto de su poética radiográfica. El título de la sección es "seudoestructuras», ellas son las que, como espectros invisibles, son atravesadas por la visión de rayos $\mathrm{X}$. Un código y un panal son estructuras que encierran una historia vivida y ordenada. El panal es la forma materializada de un instinto de agrupación y labor, y un código es la forma también materializada de una concepción de orden y justicia; en ambos casos se trata de formas orientadas con direcciones precisas. Allí afirma: «Resultan ambas de un trabajo lento de cristalización, y responden a una potencia interna de simetría y de método semejante al de las formaciones geológicas y de los sistemas óseos» (Martínez Estrada 1933:219). Los códigos del derecho son instituciones que a la manera de estructuras van cristalizando su forma en función de un lento proceso de elaboración. «Así — dice — cada institución, como cada código y cada panal, es una estructura, como lo son a su vez la moral, la religión, el idioma y las demás familias en que se agrupan los signos de la civilización y de la mera existencia vegetativa» (219).

La visión de rayos $\mathrm{X}$ pone en evidencia a las «seudoestructuras» - superficies aparentes- en la sociedad argentina: se trata de códigos que fueron trasplantados de formas de organización que nada tienen que ver con los lentos procesos orgánicos de nuestra cultura. «Paralelamente al desarrollo cristalográfico de las estructuras sociales, pueden tener lugar variaciones similares que asuman, en un momento dado, la apariencia de una estructura concreta. Son las seudoestructuras consistentes en sus líneas generales, en el contorno de su fisionomía, pero huecas de sentido y de sustancia» (220). Las seudoestructuras sociales por haber nacido fuera de «la totalidad de los instintos o las disposiciones» forman una suerte de "costra adaptada», funcionan con anomalías y se sostienen en un equilibrio precario que, subraya: «la mirada del observador profundo ve declinar o desviarse, pudiendo a veces, y a veces no, señalar los puntos débiles en que se producirá la fractura» (220).

La performática de los gestos civilizatorios que caracteriza a las políticas de modernización en Argentina produce costras adaptadas y frágiles, con contornos consistentes pero inorgánicas y huecas. El diagnóstico: osteoporosis. En las páginas siguientes, pasa de la conceptualización al análisis de objetos particulares: el de las fricciones entre los códigos del derecho y las costumbres argentinas es el primero de una serie de puntos frágiles en las «seudoestructuras», le siguen otros ejemplos de implantes similares como el de la ciudad de La Plata, el de la introducción de las máquinas industriales, los automóviles o la universidad. Refiere directamente a los rayos X cuando se ocupa de la cuestión universitaria:

En un coche de tren, por ejemplo, el estudiante de este tipo común es transparente como los rayos Roentgen: es una nébula de mala educación y de instrucción obligatoria. El tono de la voz, los gestos y hasta el tema de la plática denuncian a un grupo de jóvenes que no han subido al coche, coligados contra 
el medio, en pugna contra algo que saben y no creen. Los circunda la indiferencia de quienes ignoran cuánto cuesta saber algo bien y es natural que reaccionen así y que sean los lugares concurridos aquellos donde el que aprende aproveche el aula de oyentes desconocidos. Retoñan en los adolescentes estigmas de los viejos regímenes; están marchitos, con su sangre cansada en sus cuerpos nuevos. En primer término, el estudiante parece obligado a cumplir un deber penoso, ahíto de beber ciencia sin sed. En segundo, se diría que mira la carrera universitaria sin estímulos, sin el respeto de los que no saben y como un ejercicio ascético obligatorio para lograr un derecho. (...) Sabe de antemano que lo que aprende no vale nada si no va robustecido por la influencia de algún pariente de figuración y que después estará sólo entre sus iguales. (Martínez Estrada 1933:237-238)

Estamos ante una huella radiográfica tomada a partir de la escucha, del análisis del lenguaje y los discursos. Debajo de la superficie del estudiante, en el tono de su voz, los gestos y los temas, aparecen otras imágenes. En las páginas finales del libro, la huella se imprime en la descripción de un perfil singular. Bajo el subtítulo «La ciencia del improvisador», caracteriza a los argentinos como hombres que «a la vista» están civilizados pero que en su interior guardan el pasado de la barbarie. «Nos caracteriza, quizás entre todos los pueblos, la rapidez de concepción y la ligereza con que captamos hasta lo más hondo las alusiones sutiles, particularmente si se refieren a la estima ajena de nuestros méritos» (250). De este modo, inicia su análisis en el que señala, detrás de nuestra forma de vivir alerta, de nuestra propensión a volvernos centinelas de nosotros mismos, de nuestra prisa y autoconfianza, a través del análisis espectral, las dos líneas fundamentales de los caracteres típicos del caudillo como payador y baquiano. La velocidad de improvisación del payador y la «intuitiva ciencia del baquiano» (250), en la radiografía, son las estructuras profundas detrás de las seudoestructuras y la osteoporosis.

En términos cognoscitivos, la vanguardia se caracteriza por una actitud de sospecha. La eficacia del realismo, el naturalismo, el determinismo científico y los proyectos culturales de los Estados en proceso de modernización se vino abajo tras explosiones consecutivas: Primera Guerra, revolución en Rusia, crisis económica, Guerra Civil en España y Segunda Guerra Mundial. Una secuencia turbulenta en la que se multiplicó la cultura de masas, el crecimiento metropolitano y las migraciones intensivas. En estas coordenadas tuvo lugar el ensayo vanguardista que practicó Martínez Estrada. Bajo los mismos ejes escribieron otros ensayistas en América Latina, como el brasileño Gilberto Freyre; el cubano, Fernando Ortiz; el peruano, Mariátegui; el mexicano O. Paz, o el chileno, Benjamín Subercaseaux. Sus poéticas combaten el determinismo científico, en particular las versiones ligadas a estudios sociales. Pero, además, comparten una «sensibilidad de ideas». Se identifican con un rasgo modernista (Williams) que podríamos definir como el de una incrédula distancia nietzscheana. Martínez Estrada, por ejemplo, escribe un libro completo dedicado al filósofo alemán. Freyre fue impulsado a publicar Casa Grande y Senzala (1933) con forma de libro por el ensayista — modernista — norteamericano H.L. Mencken, quien, al igual que el argentino, también escribió un libro completo sobre Nietzsche.

La mediación de las técnicas de percepción vanguardista, en el caso de Martínez Estrada, la metáfora radiográfica, promete al ensayo producir conocimiento sobre objetos singulares, y esa es la búsqueda de estos ensayistas. Cuando recurren a la comparación y refieren a otras sociedades, 
lo hacen para señalar diferencias. Rehúyen a las leyes generales, conjeturan; no enuncian afirmaciones sobre propiedades positivas como si estas fueran distintas a las ideas especulativas: la sociedad es un texto sobre el que desarrollan interpretaciones: la colonia es una capa de discurso debajo de otras capas de lenguaje y gestos: la sexualidad de los esclavos negros y el cruce con los blancos se lee como un rastro arqueológico, la historia del tabaco y el azúcar en Cuba es el sustrato sobre el que se organiza la economía social. El ensayo vanguardista lee la cultura tal como Nietzsche propone estudiar la retórica: en el lenguaje — los gestos, las prácticas, la imaginación, los sueños de una sociedad - se encuentran, al mismo tiempo, los fundamentos que la explican y las interpretaciones que ocultan esos fundamentos; la analítica es un acto de lectura y asignación de sentido, y no de verificación externalista.

Los estudios sociales - sociología o historiografía-que proponen estos ensayos rompen con el determinismo mediante una estrategia metodológica: acercarse más a la filología o la crítica literaria que a las ciencias naturales. Tal como los historiadores de los Annales - Martínez Estrada, Freyre y Subercaseaux fueron reseñados por Braudel $(1943,1948)$ en la revista de historia francesa- el trabajo de crítica filológica les devuelve sentidos de larga duración. Temporalidades en las que la acción de los sujetos políticos es relegada a una posición menor, frente al largo período de la historia que los impulsa. El peso de los esclavos negros en Brasil es una marca de larga duración; lo mismo sucede con la centralidad del puerto de Buenos Aires o el ingreso de las máquinas. «Nuestra historia está en la paleontología y en la etnografía, en aquella más por su área, especímenes e importancia; y el historiador hubo de limitarse al trabajo de pala con que se desentierra el fósil en las guacas de las bibliotecas» (Martínez Estrada 1933:245). Así define la tarea Martínez Estrada en el apartado «Historiografía» de Radiografía de la Pampa.

La "guaca de la biblioteca» es una manera de contradecir el determinismo y la academia. No se trata del estudio de fósiles clasificados en la biblioteca; reunidos de una u otra forma según las interpretaciones científicas del caso; sino que la guaca misma está en la biblioteca: los anaqueles, los volúmenes que se leen, son el terreno de donde salen los fósiles, como por primera vez. El arqueólogo de libros busca evidencias sobre la historia humana en "guacas» culturales. La relación con los libros es análoga a la que tienen los arqueólogos con los sepulcros antiguos de los indios en Perú o Bolivia. El ensayo vanguardista busca más en el lenguaje, la imaginación, los sueños y los gestos, como los románticos, que en los datos estadísticos, como los ilustrados. El alfabetismo de los africanos esclavizados en Brasil —y su importancia en relación con la historia política一 lo encuentra Freyre leyendo un edicto policial. Entienden que las interpretaciones crean el mundo. La «guaca en la biblioteca» de Martínez Estrada es figura del carácter paradójico del objeto que estudian; se trata de una perspectiva culturalista en la que el objeto es al mismo tiempo punto de partida, punto de llegada y herramienta de análisis.

La sospecha recae sobre las convenciones. Eso es lo que destruyeron las vanguardias históricas en el arte: el realismo investiga el mundo pero en las primeras décadas del siglo XX se muestra plagado de estereotipos convencionales y normas de representación visual. Las vanguardias investigan partiendo de la base de una crítica de las convenciones visuales, verbales, sonoras, dramáticas y de movimiento. El ensayo vanguardista, por su parte, se origina en una crítica de las convenciones mentales, cuyo punto de partida se condensa en los estudios retóricos de Nietzsche: una crítica al lenguaje. Como resultado señalan la desintegración de la experiencia y proponen una analítica singular y situada. En este sentido, la ensayística latinoamericana participa de su 
época. Cae el ideal del siglo XIX, sus convenciones no son efectivas para referir al nuevo mundo. En 1933, el arco que va de la revolución en Rusia a la crisis económica de 1929 lo lleva a Martínez Estrada a dejar la poesía y a escribir en prosa. El ensayo en su etapa vanguardista se mostró, frente a una crisis sobre la cual los modelos heredados no sabían qué decir, como última instantánea de la inteligencia latinoamericana. En Argentina, más tarde, el modernismo borgeano, la sociología de Gino Germani y la Teoría Crítica empuñada por intelectuales como Juan José Sebreli, replegaron el arte a su función lúdica y atenuaron los puentes entre investigación artística y estudios sociales. Los cruces entre producción ensayística y poéticas artísticas, en Argentina, persistieron en tradiciones centrales para las artes y marginales para la investigación social: en las revistas literarias; de la ensayística de Murena a las ficciones teóricas de Emilio de Ípola, del trabajo de Massota a la novelística de David Viñas o Ricardo Piglia, de las poéticas de El Ojo Mocho y la Colección Puñaladas de la editorial Colihue a los pocos números de la revista Sitio, el ensayo como producción poética-científica ocupó un espacio de resistencia minoritaria (Scavino). Por su parte, el arte resiste en su función lúdica primordial. La actual crisis, que se abrió en 2001 y 2008, quizás sea un momento oportuno para que la investigación artística vuelva a los estudios sociales latinoamericanos con todo su esplendor imaginativo.

\section{Notas}

1 Reproducimos los primeros fragmentos de este largo poea los Andes que dan la sensación orgánica ma donde el «yo» poético refiere a su posición en el espacio: de la espina dorsal del mundo que soporta (...)

\section{PRIMERA PARTE \\ ARGENTINA \\ I \\ En la tensión nerviosa de un vuelo perentorio he logrado esta cumbre, desde la cual domino la plurifloración de este gran territorio de este inconjeturable territorio argentino.}

Estoy todo en los ojos. Mi vista aguda y vasta echa sus sondas ópticas hasta la lejanía mayor. Pachacamac, bailarín y gimnasta, en una copa azul me brinda íntegro el día.

Veo los crudos mares y tierras del avaro sur entre nieblas, hacia los círculos del polo, (...) hacia el oeste abrupto, en éxtasis y arrobos petrificados, lleno de tremendas montañas (...) luego hacia el este, al místico doméstico mar viejo que en un día de cólera se echó sobre el Godwana (...) hacia ese otro infinito añil en que confina este infinito verde de campo, campo y campo (...) y hacia el norte que abraza cinco hermanas gemelas (...)

Luego trazo un saludo de amor, indocristiano, según sus cuatro puntos: al oeste, al levante, al sur, al norte. Y queda irisada mi mano como la del Tathágata parando al elefante.

II

Después ausculto lenta, atentamente, la sonoridad de tu cuerpo,

el ritmo de tus órganos de orquestales funciones, la vibración del arpa y del piano de tus nervios. Oigo el ruido del agua en sus diversos estados y actividades: cayendo 
en cataratas, rodando por ríos y acueductos,

dando notas de sordina en el concierto;

el agua a tono menor y de pedal bajo

de las asequias y canales de riego;

(Martínez Estrada 1947:143-144)

2 Todas las citas de la poesía de Martínez Estrada están tomadas de la compilación editada por el autor en 1947 cuya referencia se consigna en la bibliografía.

3 Se trata de un procedimiento característico de las vanguardias llevado al extremo por Malevich en Cuadrado blanco sobre fondo blanco. Badiou analiza en detalle este caso en El Siglo (76-81).

4 Esa contradicción entre ideal y materia estimula los tres primeros libros de poesía, por eso son cardinales las numerosas referencias a Don Quijote de la Mancha que aparecen en zonas clave de los libros, como son los abundantes prólogos y epílogos escritos en verso.

5 En eje horizontal, Títeres de pies ligeros se inscribe en una serie vanguardista amplia. Desde 1925, Pettoruti pinta arlequines, uno de ellos en 1928. El pintor argentino participa, a su vez, de una tradición de la pintura tan extensa como la propia Comedia: Watto (1684-1721), Goya (1746-1828), Daumier (1808-1879). Tradición que desde Cézanne en adelante (Pierrot y Arlequín, 1888) practica el modernismo de forma ostensiva: los pintores rusos Yakovlev y Shukhayev realizan Arlequín y Pierrot como autorretrato a dúo, en 1914; desde 1915, Picasso pinta arlequines, de 1924 es el Arlequín y Pierrot de Derain. También pintaron arlequines Gris y Miró y tanto el circo como la Comedia del Arte en general fueron temas tratados por Chagall y la pintura rusa. La Comedia del Arte fue frecuentada por la pintura y también por la música, la poesía y el ballet: Schönberg compone su ciclo de canciones Pierrot lunaire, en 1912, a partir de los poemas de Pierrot lunaire del escritor belga, Giraud, publicados en 1884. A su vez, las pinturas de Picasso fueron realizadas en el marco de su colaboración con el ballet Parade (1916-1917), cuyo argumento fue escrito por Cocteau y la música realizada por Satie; también sobre la base de la Comedia del Arte.

La diseminación de esta forma teatral en el arte de vanguardia y el arte modernista es tan extendida que su ausencia se vuelve signo de identidad. Los muralistas mexicanos y el modernismo brasileño no la retomaron del mismo modo que en Argentina. Como recuerda Burgos en su estudio preliminar (2011), la edición de Lunario sentimental que prepara Lugones en
1926, incorpora una sección, «Taburetes para máscaras», donde incluye poemas dedicados a la Commedia: «A las máscaras», «El pierrotillo», «Cantinela de Pierrot», «Odeleta a Colombina» $\mathrm{y}$ «El Pierrot negro». En todos los casos, la incorporación de los temas de la Comedia del Arte corresponde a una estratégica poética. Escribir, pintar, componer música basados en esos temas es un modo de evitar referir a otros temas; el argumento, los personajes, esa parte de la historia ya existe, el ejercicio apunta a improvisar, una práctica artística sobre la nada. Del carnaval al modernismo, a través del romanticismo; las estructuras básicas de la Comedia del Arte, con distintas orientaciones, tienen el efecto que Martínez Estrada incorpora con los títeres. Un efecto, el del «Teatro dentro del teatro», el «Arte dentro del arte» que la propia Comedia practicaba.

6 La misma organización se repite en la reedición de la compilación que aparece como el volumen 64 de la biblioteca personal de Borges de 1985.

7 En este sentido, la variación sobre Baudelaire corresponde a una lectura del poeta francés posterior a la primera recepción modernista idealista (Cristófalo). En las Flores del mal leídas por Martínez Estrada, lo que prima es el spleen.

8 La investigadora española, Lamata Manuel, estudió estas relaciones en su tesis doctoral: «La radiología y la radiografía propone-, huella aurática ejemplar, desplegaron la realidad en profundidad, permitiendo a filósofos, poetas y pintores bascular entre la superficie y el espesor de las cosas, dejándolas aparecer confundidas y evidenciando que lo visible y lo invisible, lo conocido y lo posible se contienen mutuamente» (11).

Su trabajo aborda un arco que se extiende desde los últimos días de 1895, cuando Röntgen descubrió los rayos X, hasta los años treinta del siglo XX.

9 León Sigal describe Radiografía de la Pampa como el despliegue de un «saber espectral», analiza la «empresa radiográfica», la «perspectiva del radiógrafo» y la «prosa radiográfica», pero reduce el problema a un «procedimiento estilístico» obturando el potencial cognitivo de la figura del radiógrafo en el marco más amplio de las poéticas modernistas, incluso como contraste a su anterior exégesis del país: Argentina (1927).

10 En uno de los primeros manifiestos cubistas, Gleizes y Metzinger definen su relación con el pasado: «A Courbet le ocurrió como a aquél que contempla por vez primera el océano, que, distraído por el juego de las olas, no llega a sospechar de las profundidades; pero, lejos de nuestra intención el reprochárselo, 
pues a él le debemos los entusiasmos actuales, tan sutiles y poderosos.

Eduard Manet marca un punto más elevado. Sin embargo, su realismo es todavía deudor del idealismo de Ingres, y su "Olympia" resulta pesada al lado de "La Odalisca”. Agradezcámosle el haber transgredido las reglas caducas de la composición y el haber rebajado el valor de la anécdota hasta el punto de ser capaz de pintar "cualquier cosa". (...) Después de él, se produce la escisión. La aspiración realista se desdobla en un realismo de superficie y un realismo profundo. El primero es el realismo de los impresionistas - Monet, Sisley, etc., el segundo el de Cézanne». (23)

\section{Bibliografía}

Barthes, Roland (2004). Lo neutro. México: Siglo XXI.

Badiou, Alain (2005). El Siglo. Buenos Aires: Manantial.

Braudel, Fernand (1943). «À travers un continentd'histoire. Le Brésil et l'œuvre de Gilberto Freye». Annales. Histoire, Sciences Social. Mélangesd'histoiresociale, 4(1), 3-20.

(1948). «La règle du jeu». Annales. Histoire, Sciences Sociales, 3(4), 437-438.

Burgos, Nidia (2011). «Estudio Preliminar», en Ezequiel Martínez Estrada. Títeres de pies ligeros. Buenos Aires: Interzona, XI-XXXIV.

Cristófalo, Américo (2006). «Introducción», en Charles Baudelaire. Las flores del mal. Buenos Aires: Colihue, V-XXXIX.

Devés Valdés, Eduardo (2012). Del Ariel de Rodó a la CEPAL (1900-1950). Buenos Aires: Biblos.

Ferrer, Christian (2014). La amargura metódica: vida y obra de Ezequiel Martínez Estrada.

Freyre, Gilberto (1933). Casa Grande y Senzala. Caracas: Ayacucho, 1977.

Gleizes, Albert y Jean Metzinger (1986). Sobre el cubismo. Murcia: Colegio Oficial de Aparejadores y Arquitectos Técnicos de Murcia.

Lamata Manuel, Ana (2011). Superrealistas de la contribución de los rayos-x a la visión y presentación de la realidad en el arte de comienzos del siglo XX. Tesis de doctorado. Universidad Complutense de Madrid. Web.

Martínez Estrada, Ezequiel (1933). Radiografía de la Pampa. Madrid: Consejo Superior de Investigaciones Científicas, 1999.

(1947). Poesía. Buenos Aires: Argos.

Martínez Estrada, Ezequiel y Siné (1963). El Verdadero cuento del Tío Sam. La Habana: Casa de las Américas. Nietzsche, Friedrich (2010). Escritos sobre retórica. Madrid: Trotta.

Scavino, Dardo (2015). Las fuentes de la juventud. Genealogía de una devoción moderna. Buenos Aires: Eterna Cadencia.

Sigal, León (1996). «La radiografía de la pampa: un saber espectral», en Ezequiel Martínez Estrada. Radiografía de la Pampa. Madrid: Consejo Superior de Investigaciones Científicas, 1999.

Williams, Raymond (1989). La política del modernismo: contra los nuevos conformistas. Buenos Aires: Manantial, 1997. 